Published in final edited form as:

Thromb Res. 2020 January ; 185: 109-118. doi:10.1016/j.thromres.2019.11.024.

\title{
Equivalent inpatient mortality among direct-acting oral anticoagulant and warfarin users presenting with major hemorrhage
}

\author{
Walter Bialkowski ${ }^{a,}{ }^{,}$, Sylvia Tan ${ }^{b}$, Alan E. Mast ${ }^{\mathrm{a}}$, Joseph E. Kiss ${ }^{\mathrm{c}}$, Daryl Kor ${ }^{\mathrm{d}}$, Jerome \\ Gottschalla $^{\mathrm{a}}$, Yanyun $\mathbf{W u}^{\mathrm{e}, \mathrm{f}}$, Nareg Roubinian ${ }^{\mathrm{g}}$, Darrell Triulzi ${ }^{\mathrm{c}}$, Steve Kleinman ${ }^{\mathrm{h}}$, Young \\ Choi $^{f}$, Donald Brambillab ${ }^{b}$, Ann Zimrini, NHLBI Recipient Epidemiology and Donor \\ Evaluation (REDS)-III Study \\ aBlood Research Institute, Versiti, WI, USA \\ ${ }^{\mathrm{b}}$ Research Triangle International, MD, USA \\ cUniversity of Pittsburgh, PA, USA \\ ${ }^{\mathrm{d} D e p a r t m e n t}$ of Anesthesiology and Perioperative Medicine, Mayo Clinic, MN, USA \\ eBloodworks Northwest, Washington, USA \\ fSchool of Medicine, Yale University, CT, USA \\ gDivision of Research, Kaiser Permanente, California, USA \\ hUBC School of Medicine, Victoria, BC, Canada \\ iSchool of Medicine, University of Maryland, MD, USA
}

\begin{abstract}
Background: Extrapolation of clinical trial results comparing warfarin and direct-acting oral anticoagulant (DOAC) users experiencing major hemorrhage to clinical care is challenging due to differences seen among nonrandomized oral anticoagulant users, bleed location, and etiology. We hypothesized that inpatient all-cause-mortality among patients presenting with major hemorrhage differed based on the home-administered anticoagulant medication class, DOAC versus warfarin.
\end{abstract}

Methods: More than 1.5 million hospitalizations were screened and 3731 patients with major hemorrhage were identified in the REDS-III Recipient Database. Propensity score matching and stratification were used to account for potentially confounding factors.

Results: Inpatient all-cause-mortality was lower for DOAC (HR $=0.60,95 \%$ CI $0.45-0.80, \mathrm{p}=$ $0.0005)$ before accounting for confounding and competing events. Inpatient all-cause-mortality for 1266 propensity-score-matched patients compared using proportional hazards regression did not differ $(\mathrm{HR}=0.84,95 \% \mathrm{CI} 0.58-1.22, \mathrm{p}=0.36)$. Inpatient all-cause-mortality in stratified analyses

\footnotetext{
*Corresponding author at: Department of Computer Science, Marquette University, Milwaukee, WI, USA. walter.bialkowski@marquette.edu (W. Bialkowski).

Supplementary data to this article can be found online at https://doi.org/10.1016/j.thromres.2019.11.024.

Declaration of competing interest

AEM receives grant funding from Novo Nordisk. The other authors have no competing interests.
} 
(warfarin as reference) produced: $\mathrm{HR}=0.69(95 \% \mathrm{CI} 0.31-1.55)$ for traumatic head injuries; $\mathrm{HR}=$ 1.10 (95\%CI 0.62-1.95) for non-traumatic head injuries; HR = 0.62 (95\% CI 0.20-1.94) for traumatic, non-head injuries; and HR $=0.69$ (95\% CI 0.29-1.63) for non-traumatic, non-head injuries. Mean time to discharge was shorter for DOAC (HR $=1.17,95 \% \mathrm{CI} 1.05-1.30, \mathrm{p}=$ 0.0034 ) in the propensity score matched analysis. Plasma transfusion occurred in $42 \%$ of warfarin hospitalizations and $11 \%$ of DOAC hospitalizations. Vitamin K was administered in $63 \%$ of warfarin hospitalizations.

Conclusions: After accounting for differences in patient characteristics, location of bleed, and traumatic injury, inpatient survival was no different in patients presenting with major hemorrhage while on DOAC or warfarin.

\section{Keywords}

Direct-acting oral anticoagulant; Oral anticoagulant; Warfarin; Hemorrhage; Bleeding

\section{Introduction}

Oral anticoagulation is the primary intervention for patients with atrial fibrillation and venous thromboembolic disease. Use of oral anticoagulants is increasing due to improved adherence to published guidelines [1] and aging in the general population [2,3]. Use of the direct thrombin inhibitor (dabigatran etexilate) and three direct FXa inhibitors (rivaroxaban, apixaban, and edoxaban) [collectively, direct-acting oral anticoagulants (DOAC)] is growing due to ease of dosing, decreased need for laboratory monitoring, limited drug-drug and fooddrug interactions, and favorable efficacy and safety [4-11] relative to the vitamin K antagonist (VKA), warfarin. Major hemorrhage is the foremost complication of oral anticoagulation with an incidence of 1-5\% [12-14] and subsequent mortality reaching $11 \%$ $[15,16]$.

Several clinical trials have identified decreased mortality for DOACs relative to warfarin following major hemorrhagic events $[17,18]$. However, clinical trial patients, and particularly those consenting to follow-up research studies, are a selected group that may limit the generalizability of the results. Patients prescribed DOACs shortly after approval for clinical use may be generally healthier, distinguishing them from the population of all anticoagulated patients [19-22]. If unaccounted for, comparison of health outcomes between patients on different anticoagulant therapies could be confounded. Finally, emerging evidence indicates that bleeding risk differs between oral anticoagulants in terms of location of incident bleed (intracranial hemorrhage more common among warfarin users) [23,24]. Adequately accounting for these factors in a non-selected patient population is necessary to determine how DOACs have impacted the clinical management of major hemorrhage and potentially inform best practice. We utilized the Recipient Epidemiology and Donor Evaluation Study (REDS)-III Recipient Database [26] to identify an unselected population of anticoagulated patients presenting to 12 U.S. hospitals with major hemorrhage over a four year period. The detail in this database was used to account for known and potential confounding factors, and, to perform stratified analyses by location of bleed and traumatic injury. This investigation tested the hypothesis that inpatient all-cause-mortality among patients presenting with major hemorrhage differed based on the home-administered 
anticoagulant medication class, DOAC versus warfarin. This is the largest multi-center, observational study of patients presenting with major hemorrhage while on oral anticoagulation in the United States of which we are aware.

\section{Methods}

\subsection{Database source}

The REDS-III Recipient Database has been described previously [27]. In summary, 12 hospitals associated with one of four domestic blood centers provided coded information on all inpatient and outpatient hospital encounters during the four year period January 1, 2013 through December 31, 2016. The database uses a primary key (encounter ID) for all distinct encounters. Contained within the database are patient demographics, medical diagnoses, surgical procedures, vital signs, laboratory test results, blood product transfusions, fluid administration, respiratory support, medication use, and corresponding time data for the unselected population of all inpatient and outpatient hospitalizations. Primary, secondary, and pre-existing diagnoses (comorbidities) were also distinguishable through the use of a threelevel indicator variable. Data were aggregated for the four year study period using a conserved specification. Institutional review board approval was obtained by each of the Domestic Hubs, the Central Laboratory (Vitalant Research Institute), and the Data Coordinating Center (Research Triangle International). Informed consent was not required. Inpatient hospitalizations and mortality events in the emergency department were included in the present analysis.

\subsection{Cohort identification}

The REDS-III Recipient Database is structured such that all medications are documented in one table. Home-administered medications, such as those reported to pharmacy personnel at the time of hospital admission, are distinguished from medications administered during the hospitalization with an indicator variable. All hospitalizations for inpatients $\geq 18$ years of age with a home-administered medication of interest (warfarin, apixaban, dabigatran, edoxaban, or rivaroxaban) were identified using data contained in this table. Name and dose of all home-administered medications were available; timing of last home-administered dose was not. Exposure was defined by class of home-administered medication (DOAC versus warfarin). Hospitalizations with more than one home-administered oral anticoagulant were excluded, as were hospitalizations for which a patient received care at another institution (before or after) to avoid biases of incomplete information. Inpatient hospitalizations were studied from the time associated with the first available datum in the database through hospital discharge or death. Follow-up beyond the time of hospital discharge is not contained within the database.

\subsection{Identification of major hemorrhage}

Others [28-30] have developed validated [31] methods to identify major hemorrhagic events in healthcare databases using the criteria established by the International Society on Thrombosis and Hemostasis (ISTH) [32]. International Classification of Diseases (ICD-9) primary diagnosis codes (Appendices 1a-1b) and laboratory, transfusion, and hospitalization data were utilized as follows: i) all hospitalizations with a "critical code" listed as the 
primary diagnosis were included; and, ii) hospitalizations with a "non-critical" primary diagnostic code required at least one of the following criteria within the first complete day: (1) mortality; (2) transfusion of $\geq 2$ red blood cell products; or (3) a decline in hemoglobin $\geq$ $2.0 \mathrm{~g} / \mathrm{dL}$ between any two measurements (Fig. 1). The 2016 General Equivalence Mappings (https://www.cms.gov/Medicare/Coding/ICD10/Downloads/2016-General-EquivalenceMappings.zip) were used to forward- and reverse-map ICD-9 critical and non-critical codes due to the adoption of ICD-10 in October 2015 (Appendices 1c-1d). If the same patient presented with major hemorrhage multiple times, all of their encounters were excluded from analysis.

\subsection{Population of interest}

More than 1.5 million hospitalizations were screened for eligibility (Fig. 2). Exclusion of minors, outpatients, and hospitalizations without a medication of interest identified > 132,000 hospitalizations with at least one home-administered oral anticoagulant. The number of hospitalizations with documented home administration of any oral anticoagulant medication of interest per quarter remained approximately unchanged during the four-year study period (Fig. 3). Home-administered dabigatran use did not vary widely (range 269396), whereas the number of hospitalizations increased for home-administered apixaban (from 38 to 1597 hospitalizations) and rivaroxaban (from 449 to 1736). Accordingly, the number of hospitalizations with home-administered warfarin decreased from as many as 8028 in the third quarter of 2013 to 4983 in the final quarter of analysis ( 40\% reduction).

\subsection{Statistical considerations}

An unadjusted comparison (warfarin versus DOAC) was performed using all identified patients in the eligible cohort $(n=3731)$. Additionally, we sought to account for many reported [19-22] confounding factors simultaneously and developed a propensity score model using age, sex, home use of any anti-platelet or aspirin medication, renal dysfunction, $\mathrm{CHA}_{2} \mathrm{DS}_{2}$-VASc score (Appendix 2), and hospital (with some pooling among hospitals to satisfy model requirements). Unlike DOACs, VKA dosing is based on international normalized ratio which was available for VKA bleeders, whereas anticoagulant monitoring was not available for the DOAC bleeders. It would have been inappropriate to include predictors available for one exposure but not the other. Hence, one propensity score for each eligible hospitalization was produced that represented the probability of home-administered DOAC. Matching was performed using these scores on a one-to-one basis without replacement and a maximum difference between any two matched scores no $>0.02$ on a $0-1$ scale (caliper width). Matching more than one warfarin hospitalization to each DOAC hospitalization did not meaningfully improve statistical power because of associated losses of DOAC hospitalizations due to discrepancies between the two patient groups. Due to the strength of the association between location of bleed, traumatic injury, and mortality, stratification by location of bleed (head versus other region, using ICD code descriptions) and traumatic injury (yes versus no, as identified with leading " 8 " in ICD codes) was used to ensure an equal number of DOAC and warfarin-exposed major bleeding hospitalizations in the analysis. We also stratified by ICD-period (ICD-9 versus ICD-10) to account for potential differences in prescribing patterns over time. This produced eight logistic models in the propensity score modeling. The primary outcome was inpatient all-cause mortality. 
Power calculations (PASS software, SAS Version 9.4, SAS Institute Inc., Cary, NC) indicated $80 \%$ power to detect a hazard ratio of 1.58 and $90 \%$ power to detect a hazard ratio of 1.68. In-hospital death and discharge alive were treated as competing risks in proportional hazards models for the subdistribution hazard [33] and implemented using the PHREG statement which accounts for different lengths of hospital stay. Sensitivity for detecting a significant difference given the observed sample size and number of outcomes was assessed using a permutation test with 1000 permuted data sets. Comparisons of proportions were performed using an exact chi-squared test. Graphics were created using R.

\subsection{Outcomes assessment}

Death due to hemorrhagic causes was not available because discharge summaries were not available for all patients. Death at discharge was available, and therefore the primary outcome measure was all-cause inpatient mortality. The database contains a "Transfer" table in which all movements throughout the hospital (e.g. Emergency Department transfer to Intensive Care) were documented with associated timing data. Locations within the hospital were mapped using a conserved specification indicating when patients were receiving intensive care. ICU stays were enumerated with the requirement of a minimum of $24 \mathrm{~h}$ between any two ICU transfer records. Transfusion was determined using blood product issuance.

\section{Results}

\subsection{Unadjusted comparison indicates survival benefit for DOAC bleeders}

Application of ISTH criteria for major hemorrhage [32] to this population of interest, with exclusion of transfers, multiple major hemorrhage encounters involving the same patient, and medication combinations inconsistent with current clinical practice, identified a cohort of 3731 patients with home-administered oral anticoagulation and major hemorrhage. Allcause inpatient mortality was numerically greater in the unmatched cohort: warfarin users $(387 / 3081,12.6 \%)$ compared to DOAC users $(50 / 650,7.7 \%)$. Mean time to death was also different in the unmatched analysis (4.5 days warfarin, 6.5 days DOAC). Overall hospital length of stay was 7.6 days for warfarin users and 6.4 days for DOAC users in this unmatched cohort. Medication use, comorbid conditions, $\mathrm{CHA}_{2} \mathrm{DS}_{2}$-VASc scores, and bleed locations were different by medication class in the unmatched cohort (Table 1) and were subsequently accounted for using propensity scoring and stratification. Propensity score matches were identified for 633 of 650 (97\%) DOAC hospitalizations resulting in improved balance between the two arms of the cohort by confounding factors (Table 1). The distribution of propensity scores differed for warfarin users relative to DOAC users (Fig. 4) driven largely by differences in the prevalence of renal dysfunction, the distribution of $\mathrm{CHA}_{2} \mathrm{DS}_{2}$-VASc scores, and hospital.

\subsection{Hemorrhage management strategies}

Transfusion and medication administration that occurred during each patient's hospitalization in the matched cohort are provided in Table 2. Ninety five patients (15\%) taking the direct thrombin inhibitor, dabigatran, were analyzed with 538 patients taking one of three direct FXa inhibitors. Plasma was transfused in $42 \%$ of matched warfarin 
hospitalizations, whereas plasma was used in $11 \%$ of DOAC hospitalizations. Red blood cell transfusion was equally common in warfarin and DOAC-anticoagulated patients (52\% warfarin, $52 \%$ DOAC, $\mathrm{p}=0.87$ ), as was the transfusion of platelets (12\% warfarin, $10 \%$ DOAC, $\mathrm{p}=0.29)$. Cryoprecipitate was seldom used (5 (1\%) warfarin and $3(1 \%)$ rivaroxaban hospitalizations). When considered together, three- and four-factor PCCs were utilized in a similar number of hospitalizations by exposure class (14\% warfarin, $14 \%$ DOAC, $\mathrm{p}=0.75$ ). Vitamin $\mathrm{K}$ was utilized in $63 \%$ of warfarin- and $13 \%$ of DOACanticoagulated patients, with both vitamin $\mathrm{K}$ and plasma transfusion being used in 174 (27\%) of major hemorrhage hospitalizations for warfarin users. Recombinant factor VIIa was utilized in $4(1 \%)$ warfarin, $5(1 \%)$ rivaroxaban, and $8(8 \%)$ dabigatran hospitalizations. Idarucizumab, the specific reversal agent for dabigatran, was approved for clinical use in October 2015 and was used in five dabigatran hospitalizations.

\subsection{All-cause inpatient mortality differences eliminated in matched analysis}

Competing risk analysis, both cause-specific and subdistribution hazards regression approaches, found no difference in all-cause inpatient mortality between warfarin and DOAC users experiencing major hemorrhage. Analysis of the 633 propensity score matched pairs using the subdistribution hazards approach produced a hazard ratio (HR) of 0.84 and $95 \%$ confidence interval $(\mathrm{CI})$ of $0.58-1.22(\mathrm{p}=0.359)$ (Fig. 5a). There were 109 total deaths in the propensity score matched sample (59 warfarin; 50 DOAC). Sensitivity analysis indicated that the mortality difference would need to exceed 19 deaths (e.g. 64 warfarin, 45 DOAC, HR < 0.6) to reject the null hypothesis of no difference in all-cause inpatient mortality by medication class given the sample size and event rate (Fig. $5 \mathrm{~b}$ ). The stratified analysis produced similar results with no significant difference in all-cause inpatient mortality: traumatic head injuries ( $\mathrm{HR}=0.69,95 \% \mathrm{CI} 0.31-1.55)$, non-traumatic head injuries ( $\mathrm{HR}=1.10,95 \% \mathrm{CI} 0.62-1.95)$, traumatic non-head injuries $(\mathrm{HR}=0.62,95 \% \mathrm{CI}$ $0.20-1.94)$, and non-traumatic non-head injuries ( $\mathrm{HR}=0.69,95 \% \mathrm{CI} 0.29-1.63)$ (Supplemental Figs. 1a-1d).

\subsection{Hospital length of stay was shorter among DOAC users}

Mean hospital length of stay was 7.8 days for warfarin users and 6.4 days for DOAC users. The hazard ratio for hospital discharge, which accounts for death as a competing risk, was 1.17 (95\% CI 1.05-1.30, p = 0.003) (Fig. 6) indicating that total length of stay was significantly longer for matched warfarin patients. Statistically, the only significant hazard ratio for the stratified analysis was for non-traumatic non-head injuries ( $\mathrm{HR}=1.23,95 \% \mathrm{CI}$ $1.05-1.43, p=0.009$ ), indicating longer hospitalizations for warfarin users who experience major spontaneous non-intracranial hemorrhage relative to DOAC users. Hazard ratios were 1.21 (0.93-1.57), $1.02(0.75-1.41)$, and $1.21(0.97-1.52)$ for traumatic head, non-traumatic head, and traumatic non-head injuries, respectively.

\subsection{No difference in intensive care between DOAC and warfarin users}

There were 351 (55.4\%) matched warfarin users with at least one stay in an intensive care unit (ICU) compared to $327(51.7 \%)$ DOAC users $(\mathrm{p}=0.195)$. Altogether, there were 383 ICU stays among matched warfarin users, versus 353 stays among DOAC users. When considering an ICU stay as any stay separated from any other stay by at least $24 \mathrm{~h}$, median 
ICU length of stay was $58.7 \mathrm{~h}$ among warfarin stays and $47.7 \mathrm{~h}$ among DOAC stays. Among users with at least one ICU stay, there were $27(7.7 \%)$ matched warfarin users with multiple stays versus $24(7.3 \%)$ among DOAC users $(\mathrm{p}=0.885)$. The hazard ratio for time to discharge from the ICU for DOAC versus warfarin stays, accounting for death as a competing risk, was $1.12(95 \% \mathrm{CI} 0.97-1.31, \mathrm{p}=0.126)$, indicating that total length of ICU stay was statistically indistinguishable.

\section{Discussion}

Providers are increasingly prescribing DOACs for oral anticoagulation. Although rates of incident major hemorrhage are lower among DOAC users than warfarin users [4,7,34-36], major hemorrhage occurs at a rate of 1-4 events per 100 DOAC patient years [37-39] and, due to rapid adoption of DOACs [1,40,41], clinicians are increasingly faced with managing these crises. This analysis showed that all-cause inpatient mortality was no different between DOAC and warfarin users who presented with major hemorrhage when accounting for confounding factors and competing events. It also demonstrated that the transfusion of plasma and use of vitamin $\mathrm{K}$ were less common among DOAC users, and, their hospital stays were more than one day shorter when compared to warfarin users. Decreased transfusion and medication burden during hospitalization, combined with evidence of no difference in mortality risk and shorter length of stay, suggest that health outcomes following major hemorrhage are at least no different for DOAC users compared to warfarin users. These findings add useful perspective to a recent meta-analysis performed by Caldeira and colleagues [17], where 9/11 (82\%) of the clinical trials studied were subject to a high risk of bias because of missing data on adjusted estimates for fatal bleeding or case fatality rates for major bleeding. Additionally, because these studies assessed longer durations of follow-up (1.0-2.8 years vs. in-hospital mortality), one possible explanation for the difference in results is that potential survival benefits associated with DOAC use manifest in the period following hospital discharge.

Several studies have identified associations between patient characteristics and the likelihood of DOAC use including female sex, lower income, and higher risk of stroke [19-22]. Failure to account for these factors can influence conclusions drawn in studies of non-randomized patient groups. All-cause inpatient mortality was greater for warfarin users in our unmatched analysis. However, when we implemented propensity score matching to adjust for potentially confounding factors and produced DOAC-warfarin pairs that were more similar than the unmatched cohort, we observed that in-hospital mortality was no different between these groups. This finding is similar to data from meta-analysis of five trials, where thirty day mortality following major bleeding events prior to adjustment was greater among patients randomized to warfarin (13\%) versus dabigatran (9\%), but adjustment for age, sex, weight, and renal function eliminated this difference (adjusted OR = $0.66,95 \%$ CI 0.44-1.00) [42]. A similar reduction was identified in an analysis of 191 DOAC users compared to 615 warfarin users where 30 day mortality before adjustment produced a HR of $1.95(95 \%$ CI 1.19-3.22, $\mathrm{p}=0.008)$ with a decrease after adjustment to 1.67 (95\% CI 1.00-2.79, $\mathrm{p}=0.05$ ) [43]. Prospective study of major hemorrhagic events from 30 hospitals in the United Kingdom [44] resulted in an adjusted odds ratio for 30 day mortality that was no different for DOAC and warfarin users [0.96 (95\% C.I. 0.71-1.28, p = 
0.77)]. Verification across multiple studies (including the present study) of the finding that discrepant mortality is eliminated after adjustment for patient characteristics despite differences in data sources, statistical methodology, and sample size, supports the overall conclusion that in-hospital and 30 day mortality following major hemorrhage is not different whether on warfarin or DOAC.

Red blood cell transfusion was no different for warfarin and DOAC bleeders in our analysis (mean units, 3.66 Warfarin, 3.34 DOAC, $\mathrm{p}=0.137$ ), although other groups have reported more red blood cell transfusions for DOAC bleeders $[45,46]$. This may be associated with a higher prevalence of gastrointestinal bleeds in DOAC users from other cohorts, whereas these were equally represented in our cohort due to our use of stratification. Transfusion of plasma was more common among warfarin users $(42 \%)$ who presented with major hemorrhage in this study; more common than the administration of plasma following major bleeding events that occurred during the phase 3 clinical trials comparing dabigatran to warfarin (30\%) [10] and rivaroxaban to warfarin (20\%) [37]. Low rates of plasma transfusion among bleeding warfarin users in these clinical trials have been noted as a potential source of bias in the survival benefit reported among DOAC users [45]. Appropriate use of plasma and vitamin K could improve outcomes for warfarin bleeders; however, the use of PCCs has shown superiority to plasma transfusion in analysis of 13 clinical studies of major hemorrhage [47]. The use of either 3- or 4-factor PCCs has been variable (74\% warfarin 39\% DOAC [44], 30\% rivaroxaban [48], 41\% warfarin [45]) and PCCs were not routinely used by providers at the 12 hospitals studied revealing potential opportunities to improve clinical practice. The use of recombinant factor VIIa was uncommon for either warfarin or DOAC hospitalizations in our study and others' (1\%-2\% overall, $8 \%$ in our dabigatran events) $[42,45,46,48]$. Perhaps most surprisingly, vitamin K was administered in only 396 of 633 (63\%) propensity-score-matched warfarin users experiencing major hemorrhage in this analysis.

Risk differences related to the location of major bleeding have been documented in women aged $\geq 75$ years and men aged $\geq 85$ years for dabigatran [23] and differences in treatment efficacy have been shown for intracranial hemorrhages [49]. Two studies of outcomes following intracranial hemorrhage with approximately 100 DOAC subjects each did not identify in-hospital mortality differences [50] or 90 day mortality differences [51], whereas inpatient mortality was significantly lower for 61 DOAC users in a similar study of patients with traumatic intracranial hemorrhage $(4.9 \%$ DOAC, $20.8 \%$ warfarin, $\mathrm{p}<0.008)$ [52]. A very large, multi-hospital study of all intracranial hemorrhage events was recently published where in-hospital-mortality was less for DOAC users as compared to warfarin users (adjusted OR $=0.75,95 \%$ CI 0.69-0.81) [53], though the effect modification of traumatic injury was not investigated. Though inpatient mortality was numerically greater among intracranial hemorrhages compared to other major hemorrhages, further stratification of our sample by traumatic injury failed to identify a difference in inpatient mortality risk by medication class for patients with intracranial hemorrhage or patients with non-intracranial hemorrhage.

Similar to other observational studies, we were unable to ascertain the time of the last dose of anticoagulant, had no detailed record of medication adherence, and did not know the 
duration of time the patient was in the therapeutic range. We therefore do not know the duration of time between last medication dose, incident major hemorrhage, and arrival at the hospital. We cannot extrapolate to individual DOACs relative to each other or to warfarin. Indication for anticoagulation was not reliably available in the database; however, prospective analysis failed to identify indication as a predictor of in-hospital mortality in a recent study [44]. Extrapolation of the findings of this analysis should extend only to those patients represented in the cohort; most notably propensity scoring eliminated most patients with renal impairment, and those who were older (warfarin) and had a higher prevalence of comorbidities. Furthermore, propensity scoring accounts for potentially confounding factors only if those determinants are included in the model and some determinants of outcomes following major hemorrhage may not have been available. Despite these limitations, this analysis has key strengths. REDS-III hospitals represent a diverse collection of academic medical centers, community hospitals, and tertiary care centers. We deliberately excluded transfers into or out of network to avoid biases of incomplete information. We employed a conservative definition of major hemorrhage including the use of only primary diagnostic codes to identify eligible cases, strict restrictions on the duration between hospital arrival and declining hemoglobin, transfusion of red blood cells, or death, and avoided the use of PCCs or recombinant factor products as eligibility criteria. These strategies likely have the effect of reducing heterogeneity and associated confounding. In addition to being able to match without replacement within a very narrow propensity score (caliper width no $>0.02$ ), only 17 (<3\%) DOAC hospitalizations were not matched. Nevertheless, there is the possibility of unmeasured residual confounding having an impact on the results of this analysis and our data need to be considered in the broader context a growing body of literature on health outcomes following major bleeding among DOAC users.

Warfarin has provided 90 years of life-saving therapy for patients with atrial fibrillation and venous thromboembolic disease. Rapid adoption of DOACs has led to an uncertainty in the management of major hemorrhagic events in DOAC-anticoagulated patients. Over the four year interval studied, we saw an increase in the proportion of all hospitalizations with home administration of DOAC and a corresponding decrease in the proportion of warfarin users. Among those presenting with major hemorrhage, all-cause inpatient mortality was no different for patients with home-administered DOAC, though hospital stays were shorter when compared with warfarin users. The advent of specific reversal agents for direct factor $\mathrm{Xa}$ [54] and thrombin [55] inhibitors may further improve bleeding outcomes for some DOAC users, though more widespread use of vitamin $\mathrm{K}$ to reverse major hemorrhage among warfarin users is needed.

\section{Supplementary Material}

Refer to Web version on PubMed Central for supplementary material.

\section{Acknowledgements}

The authors wish to acknowledge NHLBI Recipient Epidemiology and Donor Evaluation Study-III (REDS-III). The NHLBI REDS-III program, domestic component, is the responsibility of the following persons:

Hubs: 
A.E. Mast and J.L. Gottschall, Versiti - Wisconsin, Milwaukee, Wisconsin.

D.J. Triulzi and J.E. Kiss, The Institute for Transfusion Medicine (ITxM, now Vitalant), Pittsburgh, Pennsylvania.

E.L. Murphy and E.M. St. Lezin, University of California, San Francisco (UCSF), and Laboratory Medicine, Department of Veterans Affairs Medical Center, San Francisco, California.

E.L. Snyder, Yale University School of Medicine, New Haven, Connecticut.

R.G. Cable, American Red Cross Blood Services, Farmington, Connecticut.

Data coordinating center:

D.J. Brambilla and M.T. Sullivan, Research Triangle International, Rockville, Maryland.

Central laboratory:

M.P. Busch and P.J. Norris, Blood Systems Research Institute (BSRI, now Vitalant), San Francisco, California.

Publication committee chair:

R.Y. Dodd, American Red Cross, Holland Laboratory, Rockville, Maryland.

Steering committee chair:

S.H. Kleinman, University of British Columbia, Victoria, British Columbia, Canada.

National Heart, Lung, and Blood Institute, National Institutes of Health:

S.A. Glynn, K.B. Malkin, and A.M. Cristman, Bethesda, Maryland.

Financial support

NHLBI contracts NHLBI HHSN2682011-00001I, -00002I, -00003I, -00004I, -00005I, -00006I, -00007I, -00008I, and -00009I.

\section{References}

[1]. Barnes GD, Lucas E, Alexander GC, Goldberger ZD, National trends in ambulatory oral anticoagulant use, The American Journal of Medicine. 128 (2015) 1300-1305 (e2). [PubMed: 26144101]

[2]. Chugh SS, Havmoeller R, Narayanan K, Singh D, Rienstra M, Benjamin EJ, Gillum RF, Kim YH, McAnulty JH Jr., Zheng ZJ, Forouzanfar MH, Naghavi M, Mensah GA, Ezzati M, Murray CJ, Worldwide epidemiology of atrial fibrillation: a global burden of disease 2010 study, Circulation. 129 (2014) 837-847. [PubMed: 24345399]

[3]. Martinez C, Cohen AT, Bamber L, Rietbrock S, Epidemiology of first and recurrent venous thromboembolism: a population-based cohort study in patients without active cancer, Thrombosis and Haemostasis. 112 (2014) 255-263. [PubMed: 24695909]

[4]. Connolly SJ, Ezekowitz MD, Yusuf S, Eikelboom J, Oldgren J, Parekh A, Pogue J, Reilly PA, Themeles E, Varrone J, Wang S, Alings M, Xavier D, Zhu J, Diaz R, Lewis BS, Darius H, Diener HC, Joyner CD, Wallentin L, Committee RLS and Investigators, Dabigatran versus warfarin in patients with atrial fibrillation, The New England Journal of Medicine. 361 (2009) 1139-1151. [PubMed: 19717844]

[5]. Patel MR, Mahaffey KW, Garg J, Pan G, Singer DE, Hacke W, Breithardt G, Halperin JL, Hankey GJ, Piccini JP, Becker RC, Nessel CC, Paolini JF, Berkowitz SD, Fox KA, Califf RM, Investigators RA, Rivaroxaban versus warfarin in nonvalvular atrial fibrillation, The New England Journal of Medicine. 365 (2011) 883-891. [PubMed: 21830957]

[6]. Granger CB, Alexander JH, McMurray JJ, Lopes RD, Hylek EM, Hanna M, Al-Khalidi HR, Ansell J, Atar D, Avezum A, Bahit MC, Diaz R, Easton JD, Ezekowitz JA, Flaker G, Garcia D, Geraldes M, Gersh BJ, Golitsyn S, Goto S, Hermosillo AG, Hohnloser SH, Horowitz J, Mohan P, 
Jansky P, Lewis BS, Lopez-Sendon JL, Pais P, Parkhomenko A, Verheugt FW, Zhu J, Wallentin L, Committees A and Investigators, Apixaban versus warfarin in patients with atrial fibrillation, The New England Journal of Medicine 365 (2011) 981-992. [PubMed: 21870978]

[7]. Giugliano RP, Ruff CT, Braunwald E, Murphy SA, Wiviott SD, Halperin JL, Waldo AL, Ezekowitz MD, Weitz JI, Spinar J, Ruzyllo W, Ruda M, Koretsune Y, Betcher J, Shi M, Grip LT, Patel SP, Patel I, Hanyok JJ, Mercuri M, Antman EM, E.A.-T. Investigators, Edoxaban versus warfarin in patients with atrial fibrillation, The New England Journal of Medicine. 369 (2013) 2093-2104. [PubMed: 24251359]

[8]. Ruff CT, Giugliano RP, Braunwald E, Hoffman EB, Deenadayalu N, Ezekowitz MD, Camm AJ, Weitz JI, Lewis BS, Parkhomenko A, Yamashita T, Antman EM, Comparison of the efficacy and safety of new oral anticoagulants with warfarin in patients with atrial fibrillation: a meta-analysis of randomised trials, Lancet. 383 (2014) 955-962. [PubMed: 24315724]

[9]. van Es N, Coppens M, Schulman S, Middeldorp S, Buller HR, Direct oral anticoagulants compared with vitamin $\mathrm{K}$ antagonists for acute venous thromboembolism: evidence from phase 3 trials, Blood. 124 (2014) 1968-1975. [PubMed: 24963045]

[10]. Majeed A, Hwang HG, Connolly SJ, Eikelboom JW, Ezekowitz MD, Wallentin L, Brueckmann M, Fraessdorf M, Yusuf S, Schulman S, Management and outcomes of major bleeding during treatment with dabigatran or warfarin, Circulation. 128 (2013) 2325-2332. [PubMed: 24081972]

[11]. Hylek EM, Ko D, Cove CL, Gaps in translation from trials to practice: non-vitamin K antagonist oral anticoagulants (NOACs) for stroke prevention in atrial fibrillation, Thrombosis and Haemostasis. 111 (2014) 783-788. [PubMed: 24573511]

[12]. Rubboli A, Becattini C, Verheugt FW, Incidence, clinical impact and risk of bleeding during oral anticoagulation therapy, World J Cardiol. 3 (2011) 351-358. [PubMed: 22125670]

[13]. Chai-Adisaksopha C, Crowther M, Isayama T, Lim W, The impact of bleeding complications in patients receiving target-specific oral anticoagulants: a systematic review and meta-analysis, Blood. 124 (2014) 2450-2458. [PubMed: 25150296]

[14]. Zelniker TA, Ruff CT, Wiviott SD, Blanc JJ, Cappato R, Nordio F, Mercuri MF, Lanz H, Antman EM, Braunwald E, Giugliano RP, Edoxaban in atrial fibrillation patients with established coronary artery disease: insights from ENGAGE AF-TIMI 48, Eur Heart J Acute Cardiovasc Care. 2048872618790561 (2018).

[15]. Chai-Adisaksopha C, Hillis C, Isayama T, Lim W, Iorio A, Crowther M, Mortality outcomes in patients receiving direct oral anticoagulants: a systematic review and meta-analysis of randomized controlled trials, Journal of Thrombosis and Haemostasis 13 (2015) 2012-2020. [PubMed: 26356595]

[16]. Testa S, Ageno W, Antonucci E, Morandini R, Beyer-Westendorf J, Paciaroni M, Righini M, Sivera P, Verhamme P, Pengo V, Poli D, Palareti G, Management of major bleeding and outcomes in patients treated with direct oral anticoagulants: results from the START-Event registry, Intern Emerg Med. 13 (2018) 1051-1058. [PubMed: 29790125]

[17]. Caldeira D, Rodrigues FB, Barra M, Santos AT, de Abreu D, Goncalves N, Pinto FJ, Ferreira JJ, Costa J, Non-vitamin K antagonist oral anticoagulants and major bleeding-related fatality in patients with atrial fibrillation and venous thromboembolism: a systematic review and metaanalysis, Heart. 101 (2015) 1204-1211. [PubMed: 26037103]

[18]. Li XS, Deitelzweig S, Keshishian A, Hamilton M, Horblyuk R, Gupta K, Luo X, Mardekian J, Friend K, Nadkarni A, Pan X, Lip GYH, Effectiveness and safety of apixaban versus warfarin in non-valvular atrial fibrillation patients in "real-world" clinical practice. A propensity-matched analysis of 76,940 patients, Thrombosis and Haemostasis. 117 (2017) 1072-1082. [PubMed: 28300870]

[19]. Desai NR, Krumme AA, Schneeweiss S, Shrank WH, Brill G, Pezalla EJ, Spettell CM, Brennan TA, Matlin OS, Avorn J, Choudhry NK, Patterns of initiation of oral anticoagulants in patients with atrial fibrillation- quality and cost implications, The American Journal of Medicine. 127 (2014) 1075-1082 el. [PubMed: 24859719]

[20]. Thompson LE, Maddox TM, Lei L, Grunwald GK, Bradley SM, Peterson PN, Masoudi FA, Turchin A, Song Y, Doros G, Davis MB, Daugherty SL, Sex differences in the use of oral anticoagulants for atrial fibrillation: a report from the National Cardiovascular Data Registry (NCDR((R))) PINNACLE registry, J Am Heart Assoc. 6 (2017). 
[21]. Steinberg BA, Shrader P, Thomas L, Ansell J, Fonarow GC, Gersh BJ, Hylek E, Kowey PR, Mahaffey KW, O'Brien EC, Singer DE, Peterson ED, Piccini JP, Outcomes Registry for Better Informed Treatment of Atrial Fibrillation I and Patients. Factors associated with non-vitamin K antagonist oral anticoagulants for stroke prevention in patients with new-onset atrial fibrillation: Results from the Outcomes Registry for Better Informed Treatment of Atrial Fibrillation II (ORBIT-AF II). American heart journal. 2017;189:40-47. [PubMed: 28625380]

[22]. Roetker NS, Lutsey PL, Zakai NA, Alonso A, Adam TJ, MacLehose RF, All-cause mortality risk with direct oral anticoagulants and warfarin in the primary treatment of venous thromboembolism, Thrombosis and Haemostasis. 118 (2018) 1637-1645. [PubMed: 30103250]

[23]. Graham DJ, Reichman ME, Wernecke M, Zhang R, South worth MR, Levenson M, Sheu TC, Mott K, Goulding MR, Houstoun M, MaCurdy TE, Worrall C, Kelman JA, Cardiovascular, bleeding, and mortality risks in elderly Medicare patients treated with dabigatran or warfarin for nonvalvular atrial fibrillation, Circulation. 131 (2015) 157-164. [PubMed: 25359164]

[24]. Miller CS, Dorreen A, Martel M, Huynh T, Barkun AN, Risk of gastrointestinal bleeding in patients taking non-vitamin k antagonist oral anticoagulants: a systematic review and metaanalysis, Clin Gastroenterol Hepatol. 15 (2017) 1674-1683 (e3). [PubMed: 28458008]

[26]. Kleinman S, Busch MP, Murphy EL, Shan H, Ness P, Glynn SA, National Heart L, Blood Institute Recipient E and Donor Evaluation S, The National Heart, Lung, and Blood Institute Recipient Epidemiology and Donor Evaluation Study (REDS-III): a research program striving to improve blood donor and transfusion recipient outcomes, Transfusion. 54 (2014) 942-955. [PubMed: 24188564]

[27]. Karafin MS, Bruhn R, Westlake M, Sullivan MT, Bialkowski W, Edgren G, Roubinian NH, Hauser RG, Kor DJ, Fleischmann D, Gottschall JL, Murphy EL, Triulzi DJ, National Heart L, Blood Institute Recipient E and Donor Evaluation S, III, Demographic and epidemiologic characterization of transfusion recipients from four US regions: evidence from the REDS-III recipient database, Transfusion. 57 (2017) 2903-2913. [PubMed: 29067705]

[28]. Boulanger L, Hauch O, Friedman M, Foster T, Dixon D, Wygant G, Menzin J, Warfarin exposure and the risk of thromboembolic and major bleeding events among medicaid patients with atrial fibrillation, Ann Pharmacother. 40 (2006) 1024-1029. [PubMed: 16735649]

[29]. Schalekamp T, Klungel OH, Souverein PC, de Boer A, Effect of oral antiplatelet agents on major bleeding in users of coumarins, Thrombosis and Haemostasis. 100 (2008) 1076-1083. [PubMed: 19132233]

[30]. Jasuja GK, Reisman JI, Miller DR, Berlowitz DR, Hylek EM, Ash AS, Ozonoff A, Zhao S, Rose AJ, Identifying major hemorrhage with automated data: results of the Veterans Affairs study to improve anticoagulation (VARIA), Thrombosis Research. 131 (2013) 31-36. [PubMed: 23158402]

[31]. Arnason T, Wells PS, van Walraven C, Forster AJ, Accuracy of coding for possible warfarin complications in hospital discharge abstracts, Thrombosis Research. 118 (2006) 253-262. [PubMed: 16081144]

[32]. Schulman S, Kearon C, Subcommittee on Control of Anticoagulation of the S, Standardization Committee of the International Society on $\mathrm{T}$ and Haemostasis, Definition of major bleeding in clinical investigations of antihemostatic medicinal products in non-surgical patients, Journal of Thrombosis and Haemostasis 3 (2005) 692-694. [PubMed: 15842354]

[33]. Fine JPaG, R, A proportional hazards model for the subdistribution of a competing risk, Journal of the American Statistical Association. 94 (1999) 496-509.

[34]. Hecker J, Marten S, Keller L, Helmert S, Michalski F, Werth S, Sahin K, Tittl L, BeyerWestendorf J, Effectiveness and safety of rivaroxaban therapy in daily-care patients with atrial fibrillation. Results from the Dresden NOAC Registry, Thrombosis and Haemostasis. 115 (2016) 939-949. [PubMed: 26791999]

[35]. Lip GY, Keshishian A, Kamble S, Pan X, Mardekian J, Horblyuk R, Hamilton M, Real-world comparison of major bleeding risk among non-valvular atrial fibrillation patients initiated on apixaban, dabigatran, rivaroxaban, or warfarin. A propensity score matched analysis, Thrombosis and Haemostasis. 116 (2016) 975-986. [PubMed: 27538358] 
[36]. Vinogradova Y, Coupland C, Hill T, Hippisley-Cox J, Risks and benefits of direct oral anticoagulants versus warfarin in a real world setting: cohort study in primary care, BMJ. 362 (2018) k2505. [PubMed: 29973392]

[37]. Piccini JP, Garg J, Patel MR, Lokhnygina Y, Goodman SG, Becker RC, Berkowitz SD, Breithardt G, Hacke W, Halperin JL, Hankey GJ, Nessel CC, Mahaffey KW, Singer DE, Califf RM, Fox KA, Investigators RA, Management of major bleeding events in patients treated with rivaroxaban vs. warfarin: results from the ROCKET AF trial, European Heart Journal. 35 (2014) 1873-1880. [PubMed: 24658769]

[38]. Beyer-Westendorf J, Forster K, Ebertz F, Gelbricht V, Schreier T, Gobelt M, Michalski F, Endig H, Sahin K, Tittl L, Weiss N, Drug persistence with rivaroxaban therapy in atrial fibrillation patients-results from the Dresden non-interventional oral anticoagulation registry, Europace. 17 (2015) 530-538. [PubMed: 25694537]

[39]. Beyer-Westendorf J, Ebertz F, Forster K, Gelbricht V, Michalski F, Kohler C, Werth S, Endig H, Pannach S, Tittl L, Sahin K, Daschkow K, Weiss N, Effectiveness and safety of dabigatran therapy in daily-care patients with atrial fibrillation. Results from the Dresden NOAC Registry, Thrombosis and Haemostasis. 113 (2015) 1247-1257. [PubMed: 25739533]

[40]. Gadsboll K, Staerk L, Fosbol EL, Sindet-Pedersen C, Gundlund A, Lip GYH, Gislason GH, Olesen JB, Increased use of oral anticoagulants in patients with atrial fibrillation: temporal trends from 2005 to 2015 in Denmark, European Heart Journal. 38 (2017) 899-906. [PubMed: 28110293]

[41]. Huiart L, Ferdynus C, Renoux C, Beaugrand A, Lafarge S, Bruneau L, Suissa S, Maillard O, Ranouil X, Trends in initiation of direct oral anticoagulant therapies for atrial fibrillation in a national population-based cross-sectional study in the French health insurance databases, BMJ Open. 8 (2018) e018180.

[42]. Majeed A, Hwang HG, Eikelboom JW, Connolly S, Wallentin L, Feuring M, Brueckmann M, Noack H, Yusuf S, Schulman S, Effectiveness and outcome of management strategies for dabigatran- or warfarin-related major bleeding events, Thrombosis Research. 140 (2016) 81-88. [PubMed: 26908016]

[43]. Becattini C, Franco L, Beyer-Westendorf J, Masotti L, Nitti C, Vanni S, Manina G, Cattinelli S, Cappelli R, Sbrojavacca R, Pomero F, Marten S, Agnelli G, Major bleeding with vitamin K antagonists or direct oral anticoagulants in real-life, International Journal of Cardiology. 227 (2017) 261-266. [PubMed: 27843050]

[44]. Green L, Tan J, Morris JK, Alikhan R, Curry N, Everington T, Maclean R, Saja K, Stanworth S, Tait C, MacCallum P, A three-year prospective study of the presentation and clinical outcomes of major bleeding episodes associated with oral anticoagulant use in the UK (ORANGE study), Haematologica. 103 (2018) 738-745. [PubMed: 29371325]

[45]. Xu Y, Schulman S, Dowlatshahi D, Holbrook AM, Simpson CS, Shepherd LE, Wells PS, Giulivi A, Gomes T, Mamdani M, Khuu W, Frymire E, Johnson AP and Bleeding Effected by Direct Oral Anticoagulants Study G. Direct Oral Anticoagulant- or Warfarin-Related Major Bleeding: Characteristics, Reversal Strategies, and Outcomes From a Multicenter Observational Study. Chest. 2017;152:81-91. [PubMed: 28219635]

[46]. Milling TJ, Fromm C, Ganetsky M, Pallin DJ, Cong J, Singer AJ, Management of major bleeding events in patients treated with dabigatran for nonvalvular atrial fibrillation: a retrospective, multicenter review, Ann Emerg Med. 69 (2017) 531-540. [PubMed: 28196608]

[47]. Chai-Adisaksopha C, Hillis C, Siegal DM, Movilla R, Heddle N, Iorio A, Crowther M, Prothrombin complex concentrates versus fresh frozen plasma for warfarin reversal. A systematic review and meta-analysis, Thrombosis and Haemostasis. 116 (2016) 879-890. [PubMed: 27488143]

[48]. Burgos KD, Sienko SE, Hoffman JL, Koerber JM, Smythe MA, Characteristics, management, and outcomes of patients with atrial fibrillation experiencing a major bleeding event while on rivaroxaban, Clin Appl Thromb Hemost. 24 (2018) 372-378. [PubMed: 28301906]

[49]. Majeed A, Agren A, Holmstrom M, Bruzelius M, Chaireti R, Odeberg J, Hempel EL, Magnusson M, Frisk T, Schulman S, Management of rivaroxaban- or apixaban-associated major bleeding with prothrombin complex concentrates: a cohort study, Blood. 130 (2017) 1706-1712. [PubMed: 28835439] 
[50]. Alonso A, Bengtson LG, MacLehose RF, Lutsey PL, Chen LY, Lakshminarayan K, Intracranial hemorrhage mortality in atrial fibrillation patients treated with dabigatran or warfarin, Stroke; a Journal of Cerebral Circulation. 45 (2014) 2286-2291.

[51]. Wilson D, Seiffge DJ, Traenka C, Basir G, Purrucker JC, Rizos T, Sobowale OA, Sallinen H, Yeh SJ, Wu TY, Ferrigno M, Houben R, Schreuder F, Perry LA, Tanaka J, Boulanger M, Al-Shahi Salman R, Jager HR, Ambler G, Shakeshaft C, Yakushiji Y, Choi PMC, Staals J, Cordonnier C, Jeng JS, Veltkamp R, Dowlatshahi D, Engelter ST, Parry-Jones AR, Meretoja A, Werring DJ and And the C-C. Outcome of intracerebral hemorrhage associated with different oral anticoagulants. Neurology. 2017;88:1693-1700. [PubMed: 28381513]

[52]. Feeney JM, Santone E, DiFiori M, Kis L, Jayaraman V, Montgomery SC, Compared to warfarin, direct oral anticoagulants are associated with lower mortality in patients with blunt traumatic intracranial hemorrhage: a TQIP study, J Trauma Acute Care Surg. 81 (2016) 843-848. [PubMed: 27602897]

[53]. Inohara T, Xian Y, Liang L, Matsouaka RA, Saver JL, Smith EE, Schwamm LH, Reeves MJ, Hernandez AF, Bhatt DL, Peterson ED, Fonarow GC, Association of intracerebral hemorrhage among patients taking non-vitamin $\mathrm{K}$ antagonist vs vitamin $\mathrm{K}$ antagonist oral anticoagulants with in-hospital mortality, JAMA: The Journal of the American Medical Association. 319 (2018) 463473. [PubMed: 29372247]

[54]. Heo YA, Andexanet alfa: first global approval, Drugs. 78 (2018) 1049-1055. [PubMed: 29926311]

[55]. Burness CB, Idarucizumab: first global approval, Drugs. 75 (2015) 2155-2161. [PubMed: 26578027] 


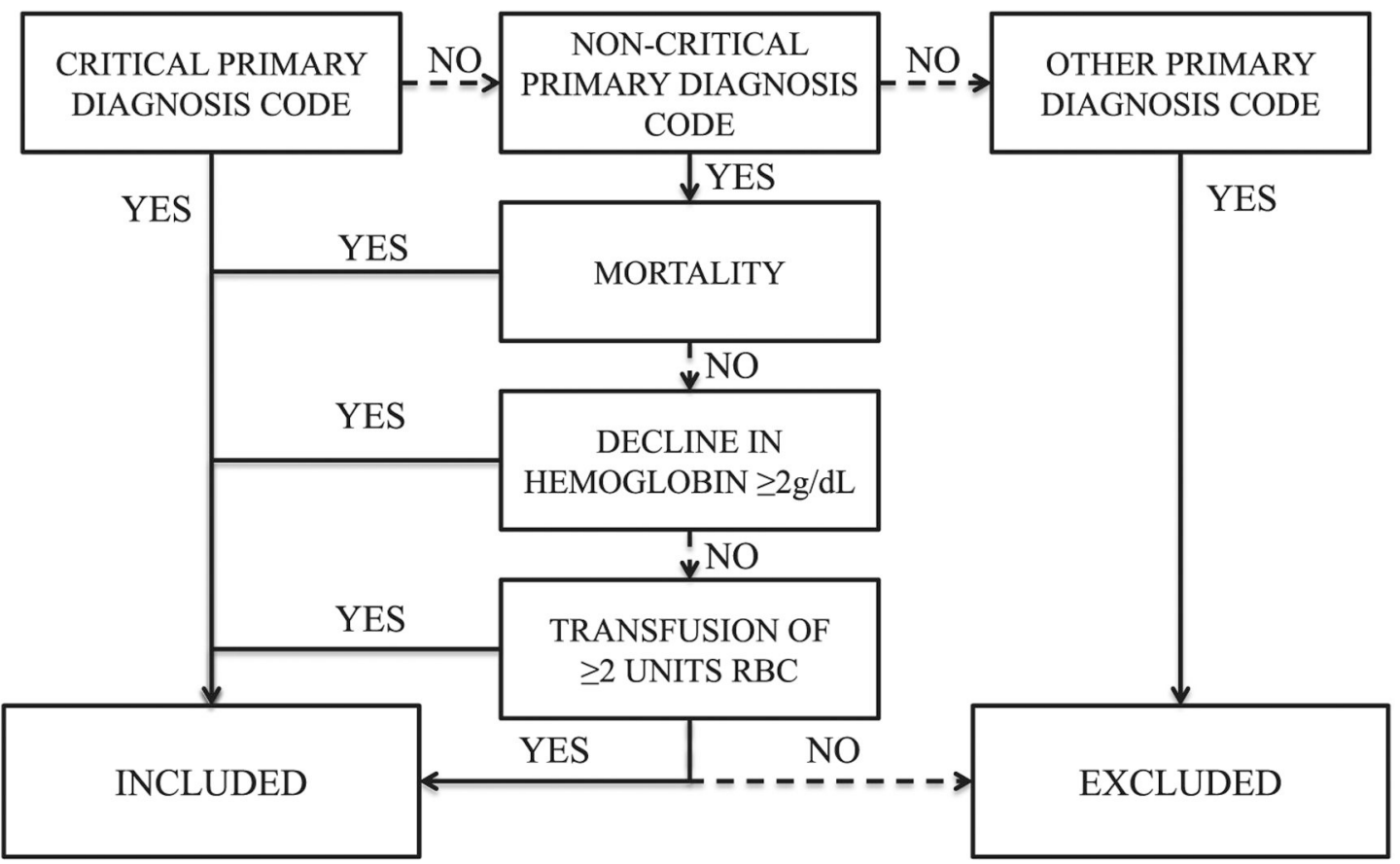

Fig. 1.

Decision schematic for identifying major bleeding. 


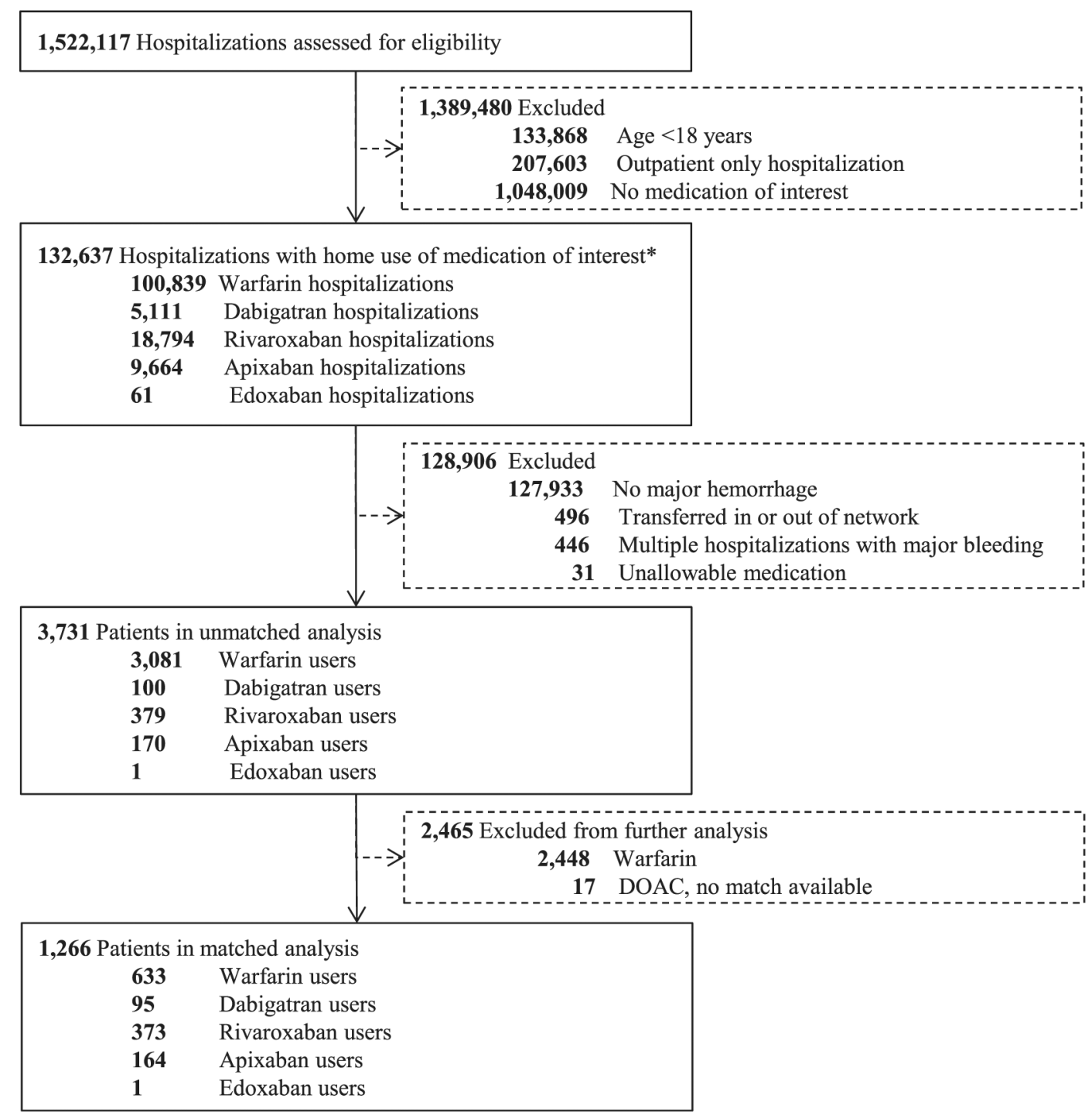

Fig. 2.

Hospitalization eligibility flowchart showing hospitalizations assessed for eligibility, purposes for exclusion from analysis, and the final propensity score matched analytic cohort. Reasons for exclusion are iterative and sequential. *numbers in this box are not additive due to hospitalizations having more than one medication of interest that are subsequently excluded. 


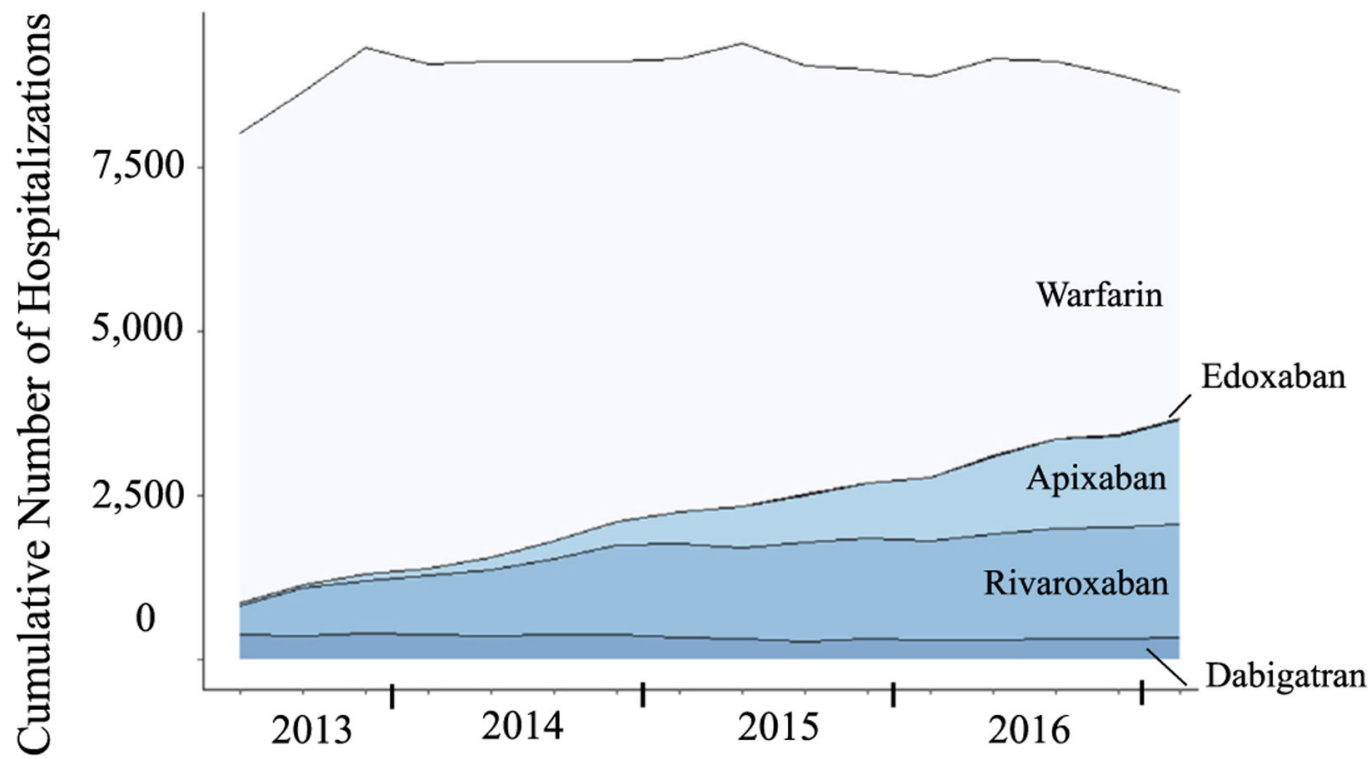

\section{Calendar Year}

Fig. 3.

Stacked area graph with each polygon representing the number of encounters by medication of interest for each quarter between January 1, 2013 and December 31, 2016. The total height of all polygons for a given quarter represents the total number of encounters for all medications combined. 


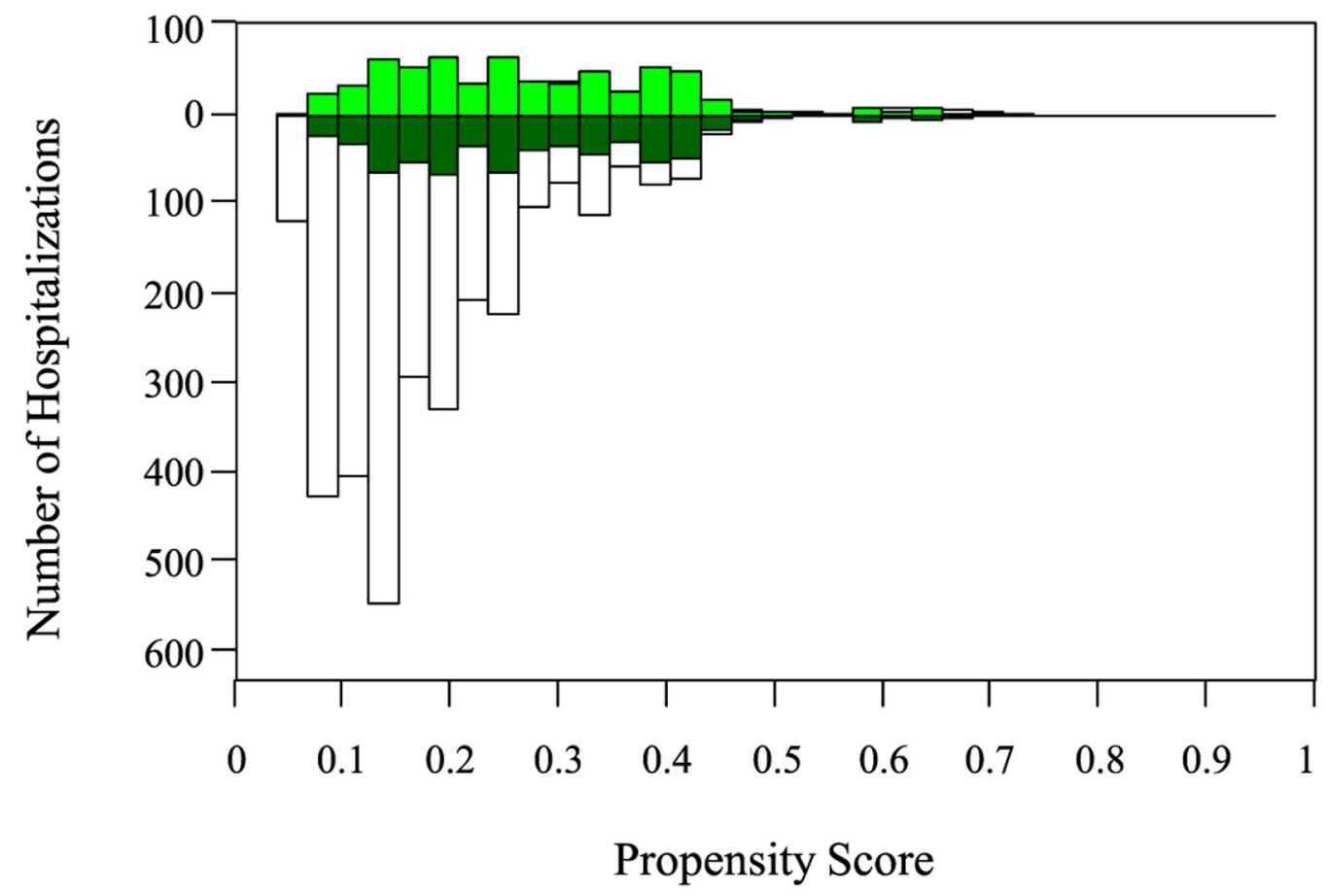

Fig. 4.

Mirrored histogram showing the distribution of propensity scores before (white) and after (green) matching. DOAC hospitalizations are shown above the horizontal zero line (light green) and warfarin hospitalizations are shown below the horizontal zero line (dark green). (For interpretation of the references to colour in this figure legend, the reader is referred to the web version of this article.) 


\section{$\mathbf{a}$}

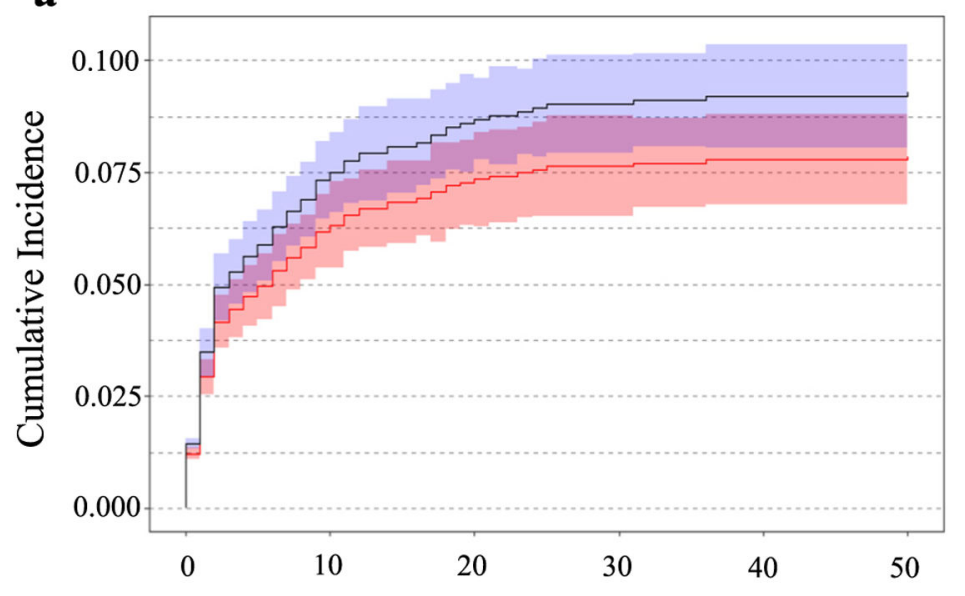

Time to Death (days)

b

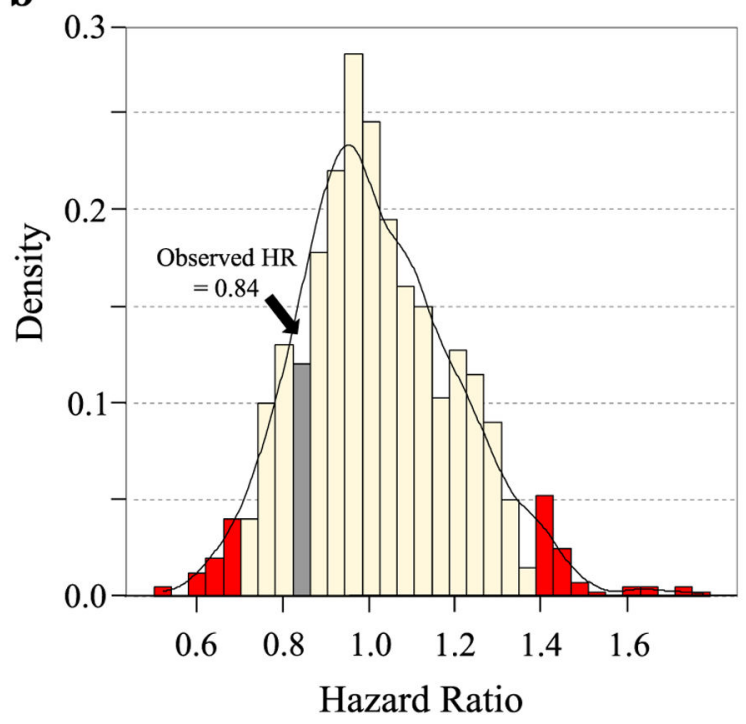

Fig. 5.

a. Cumulative incidence functions of mortality for warfarin (blue) and DOAC (red) with overall hazard ratio $=0.84$ and $95 \%$ confidence interval of $0.58-1.22(\mathrm{p}=0.359)$.

Overlapping 95\% confidence intervals appear purple. b. Histogram showing results from sensitivity analysis of all-cause mortality. Hazard ratio values falling in the area of rejection $(\mathrm{p}<0.025)$ are shown in red; values in the area of non-rejection $(0.025<\mathrm{p}<0.975)$ are shown in yellow; the bar shown in grey represents the interval in which the observed hazard ratio fell; a kernel density plot is overlaid as the solid black line. (For interpretation of the references to colour in this figure legend, the reader is referred to the web version of this article.) 


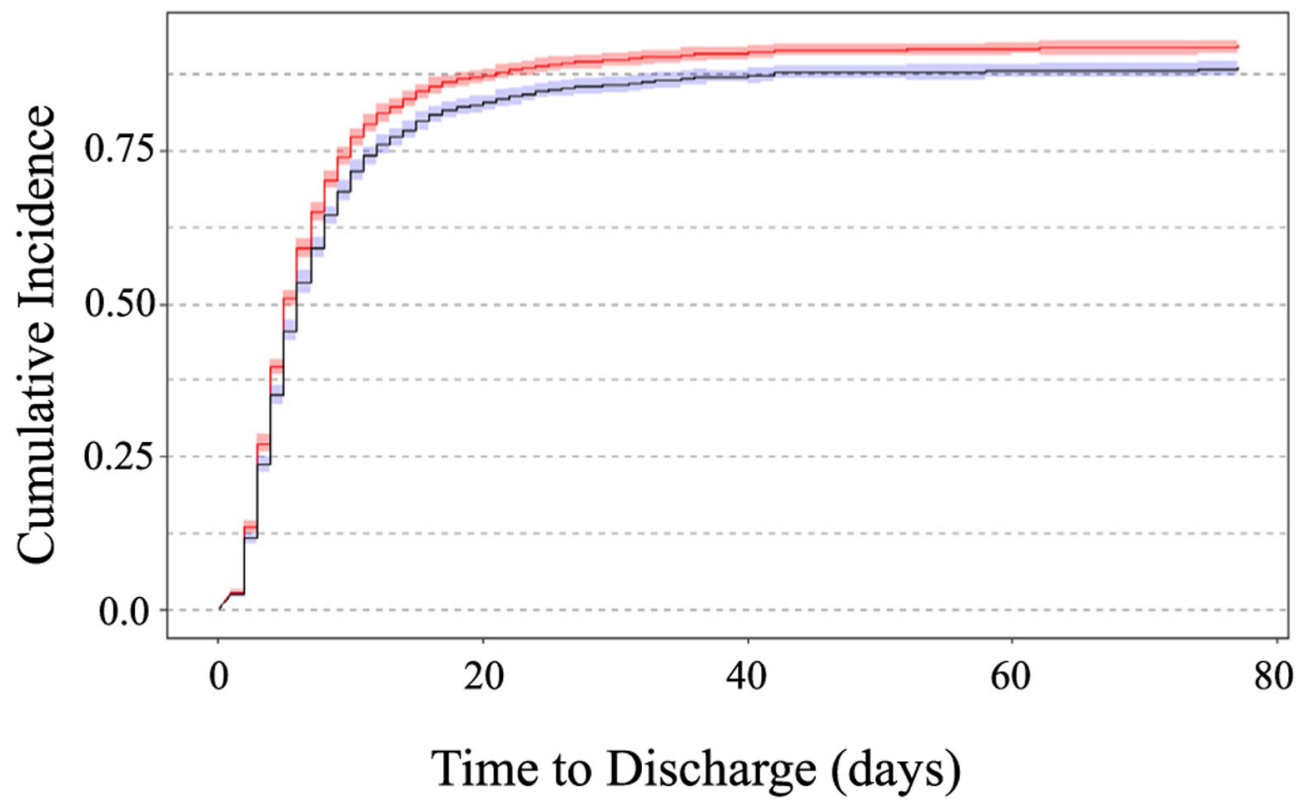

Fig. 6.

Cumulative incidence functions of overall hospital length of stay for warfarin (blue) and DOAC (red) with overall hazard ratio $=1.17(95 \%$ CI 1.05-1.30, $\mathrm{p}=0.003)$. Overlapping 95\% confidence intervals appear purple. (For interpretation of the references to colour in this figure legend, the reader is referred to the web version of this article.) 


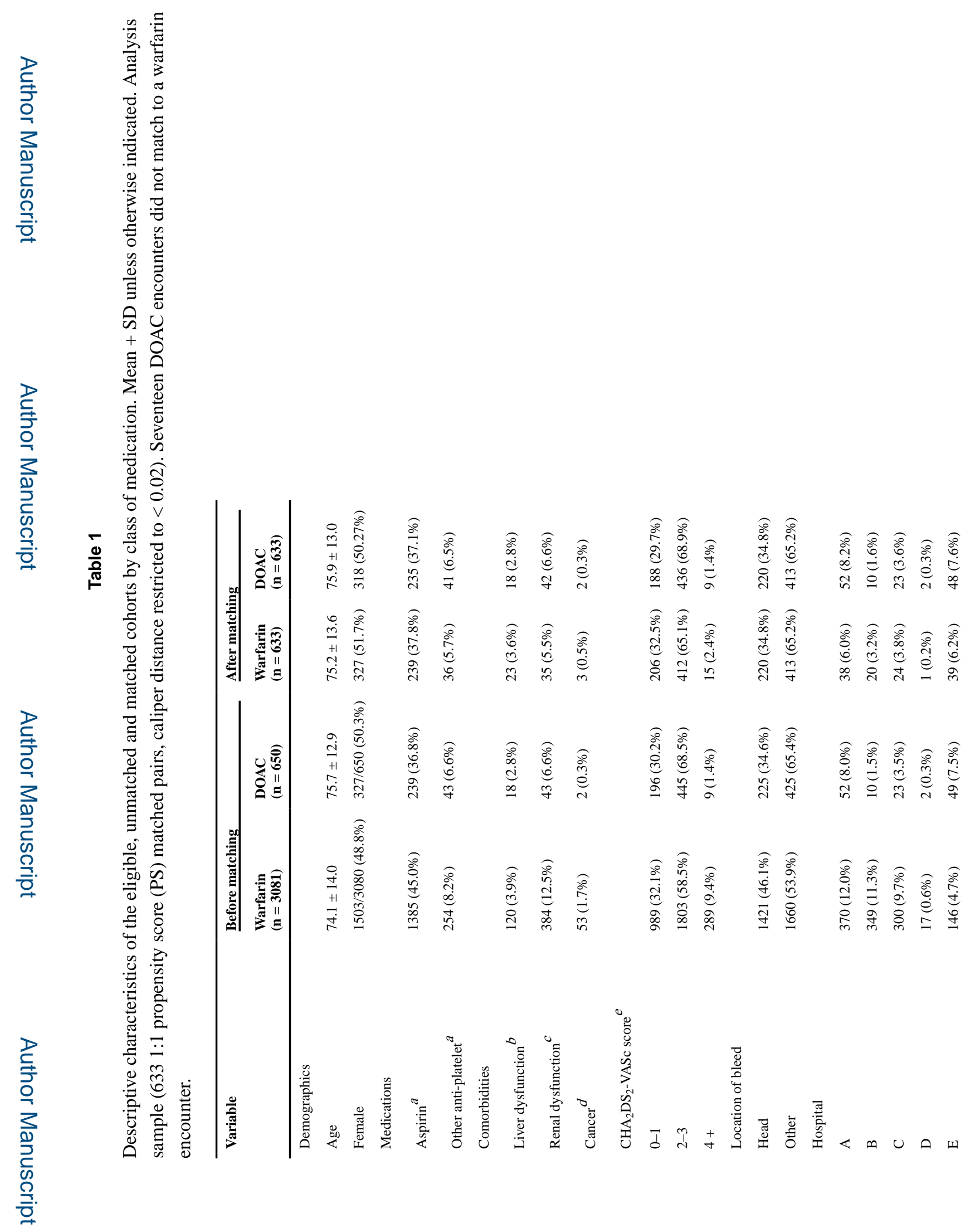

Thromb Res. Author manuscript; available in PMC 2021 January 01. 


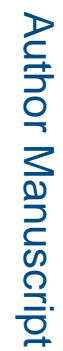

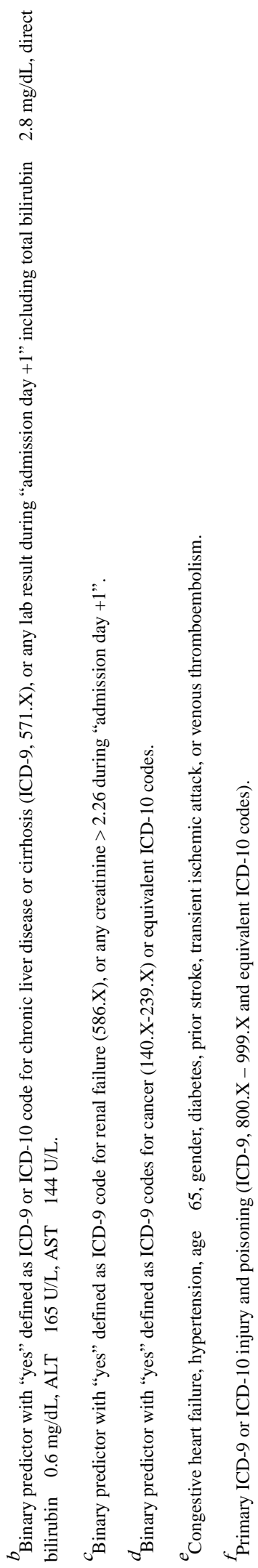

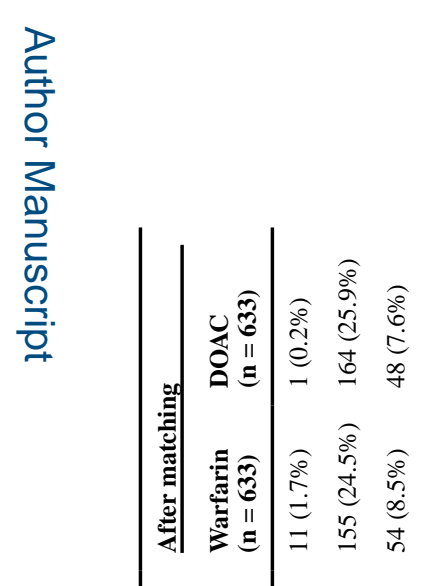

$$
\text { ำ }
$$

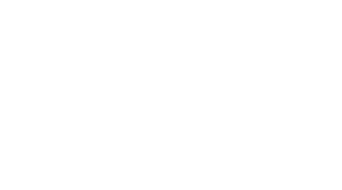

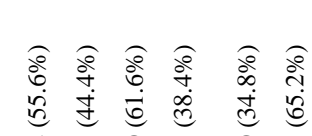

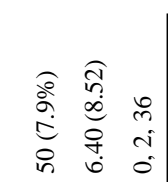

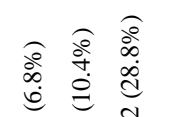

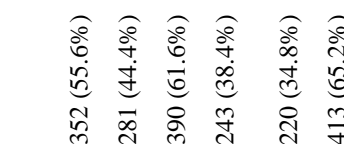

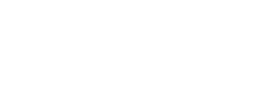




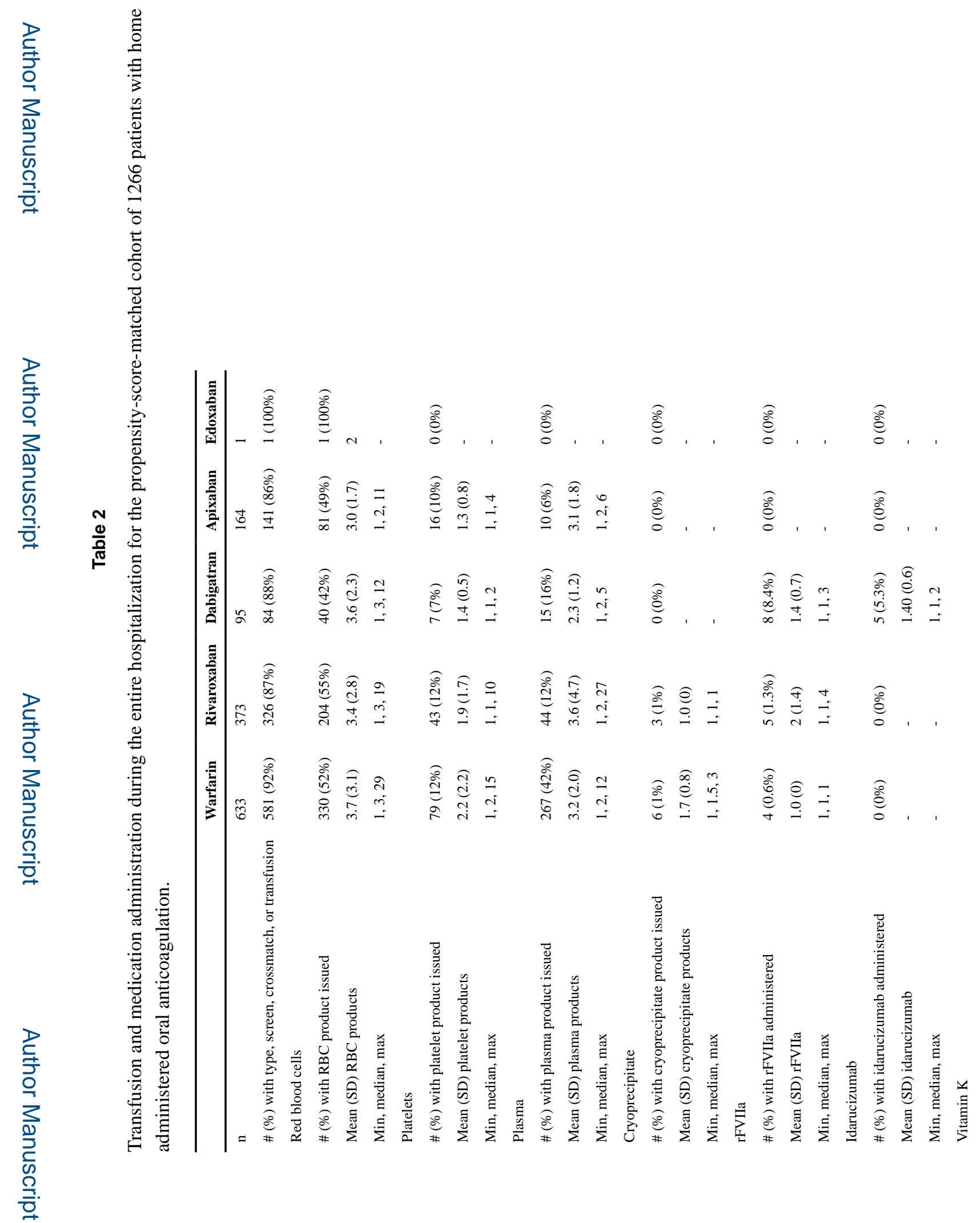

Thromb Res. Author manuscript; available in PMC 2021 January 01. 
Bialkowski et al.

Page 24

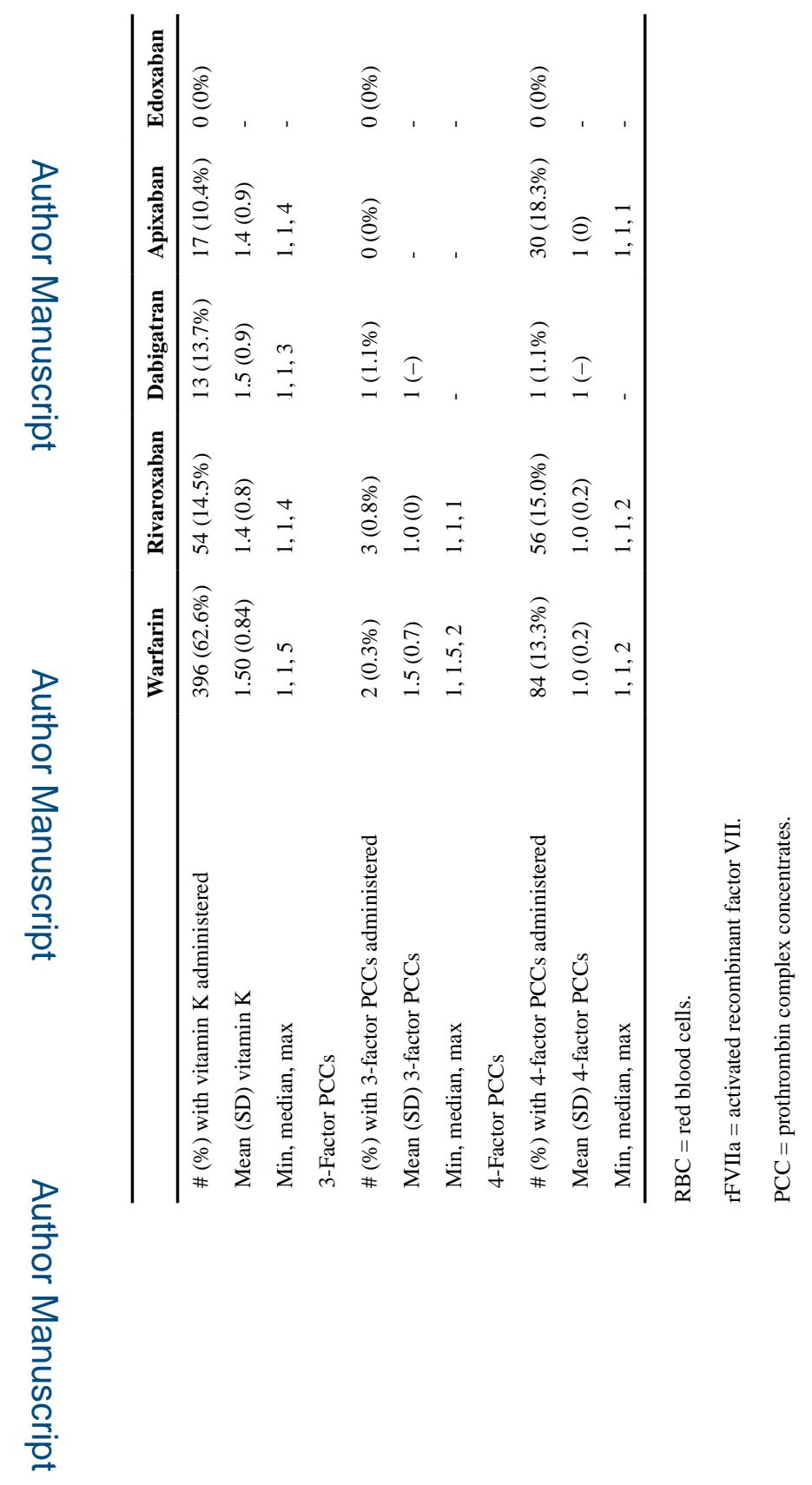

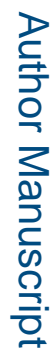

Thromb Res. Author manuscript; available in PMC 2021 January 01. 